\title{
Effects of a Gestational Weight Gain Restriction Program for Obese Pregnant Women: Childrens Weight Development during the First Five Years of Life
}

Ing-Marie Claesson, Gunilla Sydsjö, Elisabeth Olhager, Carin Oldin and Ann Josefsson

\section{Linköping University Post Print}

\section{Tweet}

N.B.: When citing this work, cite the original article.

Original Publication:

Ing-Marie Claesson, Gunilla Sydsjö, Elisabeth Olhager, Carin Oldin and Ann Josefsson, Effects of a Gestational Weight Gain Restriction Program for Obese Pregnant Women: Childrens Weight Development during the First Five Years of Life, 2016, CHILDHOOD OBESITY, (12), 3, 162-170.

http://dx.doi.org/10.1089/chi.2015.0177

Copyright: Mary Ann Liebert

http://www.liebertpub.com/

Postprint available at: Linköping University Electronic Press

http://urn.kb.se/resolve?urn=urn:nbn:se:liu:diva-129485 
Effects of a gestational weight gain restriction program for obese pregnant women: Children's weight development during the first five years of life

Ing-Marie Claesson ${ }^{1}$, Gunilla Sydsjö ${ }^{1}$, Elisabeth Olhager ${ }^{2}$, Carin Oldin ${ }^{3}$, Ann Josefsson ${ }^{1}$.

${ }^{1}$ Department of Obstetrics and Gynaecology, and Department of Clinical and Experimental Medicine, Linköping University, Linköping, Sweden

E-mail: Ing-Marie.claesson@liu.se; Gunilla.Sydsjo@regionostergotland.se; Ann.Josefsson@regionostergotland.se

${ }^{2}$ Department of Clinical Sciences and Department of Paediatrics, Lund University, Sweden

E-mail: Elisabeth.Olhager@skane.se

${ }^{3}$ Child Health Services, Public health and health care, Region Jönköping County, Jönköping, Sweden E-mail: Carin.Oldin@rjl.se

\section{Acknowledgements}

This study was supported by grants from The Health Research Council of the Southeast of Sweden and ALF, County Council of Östergötland

Author Disclosure Statement: None of the authors report any conflict of interest and no specific funding.

Correspondence:

Ing-Marie Claesson

Department of Obstetrics and Gynaecology and Department of Clinical and Experimental Medicine

Faculty of Medicine

Linköping University

SE - 58183 Linköping, Sweden

Tel. +46101032923

Fax: +4613148156

Email: Ing-Marie.Claesson@liu.se 


\begin{abstract}
Background: Maternal prepregnancy obesity (Body Mass Index, BMI $\geq 30 \mathrm{~kg} / \mathrm{m}^{2}$ ) and excessive gestational weight gain (GWG) have shown a strong positive association with a higher BMI and risk of obesity in the offspring. The aim of this study is to estimate the effect of a GWG restriction program for obese pregnant women on the children's BMI at 5 years of age and weight-forlength/height (WL/H) development from two months of age until 5 years of age.
\end{abstract}

Methods: This was a follow-up study of 302 children (137 children in an intervention group and 165 children in a control group) whose mothers participated in a weight gain restriction program during pregnancy.

Results: BMI at five years of age did not differ between girls and boys in the intervention- and control group. The degree of maternal GWG, $<7 \mathrm{~kg}$ or $\geq 7 \mathrm{~kg}$, did not affect the offspring's WL/H. Compared with Swedish reference data just over half of the children in both the intervention- and control group had a BMI within the average range, whereas slightly more than one-third of the children had a higher BMI.

Conclusion: Despite a comprehensive gestational intervention program for obese women, containing individual weekly visits and opportunity to participate in aqua aerobic classes, there were no differences between BMI or weight development among the offspring at 5 years of age in the intervention- and control group. 


\section{Introduction}

Obesity (Body Mass Index, BMI $\geq 30 \mathrm{~kg} / \mathrm{m}^{2}$ ) in pregnancy poses a high risk for complications during pregnancy and childbirth (e.g. gestational diabetes mellitus, caesarean delivery and macrosomia) [1-3]. Excessive gestational weight gain (GWG) may further worsen the situation for both the mother and the neonate [4, 5]. Maternal pre-pregnancy obesity and excessive GWG have shown a strong positive association with a higher BMI and risk of obesity in the offspring [6-9]. Also, childhood obesity may result in adverse outcomes later in life [9-11].

In studies carried out in Finland, the effect of an intervention, undertaken during pregnancy or in early postpartum, on the offspring's weight gain during the first four years of life was examined [12-14]. The intervention given during pregnancy was not effective in slowing children's weight gain until four years of age, whereas the intervention given postpartum showed a slower increase of standardized zscore of weight-for-length/height (ZWL/H) and standardized z-score of BMI (ZBMI) for children in the intervention group compared with a control group.

We have in previous studies shown that an intervention program designed to restrict the GWG $<7 \mathrm{~kg}$ was effective among obese pregnant women [15-17]. The women in the intervention group gained less weight during pregnancy and had a lower weight at the follow-up assessments two and six years after childbirth, compared with the women in the control group. The aim of this study was to estimate the effect of GWG restriction program for obese pregnant women on the children's BMI at 5 years of age and weight-for-length/height $(\mathrm{WL} / \mathrm{H})$ development from 2 months of age until 5 years of age. 


\section{Patients and Methods}

The study groups comprise children of obese pregnant women who participated in an intervention study during 2004-2006 at the antenatal care clinic (ANC) in Linköping. A control group of obese pregnant women was recruited from the ANCs in two nearby cities. The original study and the followup studies are described elsewhere and summarized briefly below [15-17]. The intervention program consisted of individual weekly visits during pregnancy and every six months during the first two years after childbirth, with a specially trained midwife aiming to change behaviours regarding nutrition and physical activity. The participants were also invited to join aqua aerobic classes especially designed for obese women. A total of 155 women (67.4\%) completed the intervention program. The control group consisted of 193 pregnant obese women who followed the routine program at the ANCs. All women were recruited and included in the study in early pregnancy, i.e. before gestational week 15 .

In Sweden all families are offered preventive health care for their children throughout childhood and youth. The preventive health care program is free of charge and reaches almost $100 \%$ of all children [18]. At the child welfare center (CWC) and the pupil health care children are advised to attend the regular health program (weight- and length/height development, physical health, immunizations, cognitive- and linguistic development).

\section{Subjects}

A description of the population in the original- and follow-up studies is displayed in Figure 1. Mothers ( $n=343$ ) from the original study were sent a letter with information about the follow-up of their children. Parents of 138 children agreed to participate in the follow up study and 166 from the control group. In the former group one child was excluded because of genetic disorder (Down syndrome). Parents of nine children refrained from participation. Thus 137 children (89.0 \%) from the intervention group took part in the follow-up study. In the latter group one child was excluded because of disability (delayed physical and mental development) and one woman could not be reached. Nineteen parents refrained from participation, thus 165 children (85.5 \%) from the control group participated in the follow-up study. 


\section{Data collection}

Data were manually extracted from the records by the main author (IMC): weight and height at 2, 6, 12 and 18 months of age and at 4 and 5 years of age. Information about illness, disability, parental smoking habits and breastfeeding were also obtained. Maternal and children background characteristics were obtained from antenatal, delivery and neonatal records.

\section{Statistics}

All analyses were performed using the IBM SPSS program, version 22.0 (IBM Corp., Armonk, NY, USA). Statistical significance was defined as (two-sided) $\mathrm{p} \leq 0.05$. Before analysing the weight changes, the assumption of these variables being normally distributed was validated using the Kolmogorov-Smirnov test. This assumption was not confirmed. Mann Whitney U-test was therefore used as method of analysis on all continuous variables. Group differences were estimated by using Pearson chi-square test and Fischer's Exact Test on categorical variables. To make a more comprehensive assessment of group differences, linear regressions were performed with BMI at 5 years of age as dependent variables.The size of the child was analysed using weight and length/height. The value was converted to WLH (e.g. weight/length or height) and its standard score (z-score) was used. The child's BMI at 5 years of age was analysed with respect to BMI reference values, expressed in mean and standard deviation, for Swedish children [19].

\section{Ethics}

All parents have given informed consent. The study was approved by the Regional Ethical Review Board in Linköping, Sweden. Dnr 2010/400-31. 


\section{Results}

Maternal and children characteristics are displayed in Table 1. A greater percentage of children in the intervention group had been breastfed at some time during infancy than those in the control group ( $p=$ 0.013). For the participants in this follow up there was also a significant difference in GWG ( $p=$ $>0.001$ and $p=0.005)$.

The children's BMI and ZBMI at 5 years of age and also in relation to maternal GWG are displayed in Table 2. There were no differences between girls and boys in the intervention- and control groups, except among boys whose mothers gained $<7 \mathrm{~kg}$ during the pregnancy. Boys in the intervention group had a lower BMI than boys in the control group ( $\mathrm{p}=0.039$ ). However, the significant difference disappeared after adjusting for socio-demographic factors and breastfeeding $(\mathrm{p}=0.407)$. The children's BMI was also analysed with respect to national reference data. Slightly more than half of the children in both the intervention- and control group had BMI that fell within the average range, whereas just over one third of the children had higher BMI (Table 3).

The distributions of standardized scores of WL/H among boys and girls belonging to the interventionand control group, from two months of age until 5 years of age, are displayed in Figure 2. There were no differences in the ZWL/H development among boys and girls in the two groups. 


\section{Discussion}

In this follow-up study we found that by comparison with Swedish reference data more than one third of the children, irrespective of gender or group, had a BMI indicating overweight or obesity. The prevalence of overweight and obesity among 4-years-old Swedish children in two different Swedish districts, was in year $201410.6 \%$ and $2.2 \%$, respectively [20]. We found no difference between the children in the intervention- and control groups in BMI at 5 years of age or in $\mathrm{WL} / \mathrm{H}$ development during the first five years of life in relation to GWG of the mother.

We found no crucial differences concerning BMI and development of $\mathrm{WL} / \mathrm{H}$ during the first five years of life, between the children in the intervention- and control group. But for the women the intervention had a positive effect on the GWG and their own weight development six years after participation in a weight gain restriction program $[15,17]$. We expected that the mother's change to healthier lifestyle habits during pregnancy would have influenced her child's weight development during childhood, however this was not evident in this study. Whereas the original study had a high level of statistic power to detect difference in maternal GWG, this follow-up study could not, despite a high rate of participation, reach the same level. Significantly more participants might have been needed to demonstrate a difference. One can also speculate about whether a continued comprehensive intervention program at CWC, designed to support the newly formed family in establishing new habits would give a different result. Furthermore from another point of view, it may be desirable to examine if genetic as well as epigenetic factors transmitted from the parents to the offspring might be involved already at the moment of conception. In a recent study on fruit flies it was shown that paternal sugar intake elicits obesity in offspring [21]. The interpretation of the findings from this fruit fly study was that the epigenetic memory is created very early in fruit flies, probably at the moment of conception. This insight indicates that one should consider the need for pre-pregnancy counselling for obese women as well as men. Also findings in a clinical study emphasize the importance of maintaining a healthy weight during the reproductive years [22]. The results also showed that a greater maternal prepregnancy weight was associated with obesity among the children. The mothers GWG, i.e. $<7 \mathrm{~kg} / \geq 7$ $\mathrm{kg}$, had no impact on the BMI of the offspring in our study. This result is in contrast to findings in the 
British study [22] which found that offspring of women with GWG above IOM-recommended level [23], were more likely to have a greater BMI. The same study also showed that any maternal weight gain during the first 14 gestational weeks was associated with increased obesity in offspring, whereas only maternal GWG >500 g/w between gestational week 14 and 36 was associated with obesity in offspring.

Mustila and co-authors in Finland have in two studies, encompassing women in different BMI classes, investigated the effect of gestational and postpartum lifestyle counselling on the offspring's weight gain $[12,14]$. In the first 4-year follow-up study they demonstrated that among the offspring in the intervention group and the control group, there was no difference in the increase of ZBMI or $\mathrm{ZWL} / \mathrm{H}$ until the age of 4 years [12]. This result differs from the result in the second 4-years follow-up study among mothers with infants at the age of 2 - 10 months who participated in an intervention postpartum [14]. The increase of the ZBMI and $\mathrm{ZWL} / \mathrm{H}$, between 2 and 4 years of age was slower among the offspring in the postpartum intervention group than in the control group [14]. In a recent Danish follow-up study of a gestational intervention program for obese women, no ZBMI differences at three years of age were detected between the intervention- and control groups [24]. These results from studies designed as a gestational lifestyle counselling program are in line with our results. On the other hand the results from the Danish study [24] intended to give a postnatal lifestyle counselling differ from our findings. The women in the intervention group in the present study were offered, in addition to the gestational intervention program, an individual visit every six months during the first two years after childbirth in order to discuss behaviour regarding nutrition and physical activity.

An association between maternal BMI and/or GWG and the BMI of offspring have been investigated in some large cohort studies [25-27]. A Norwegian study found a positive association between both maternal pre-pregnancy BMI and GWG and the mean BMI of the offspring at 3 years of age [25]. Similar results are reported in a European study which investigated ante-, peri- and postnatal risk factors on risk of obesity in children at $4 \mathrm{r}$ and 8 years of age [26]. GWG $>25 \mathrm{~kg}$ posed after adjustment a twofold risk of obesity for the offspring. A German study encompassing data of motherchild dyads, showed an association between abdominal adiposity among 6-year old children with pre- 
pregnancy-obese mothers and continuous GWG [27]. On the other hand, when GWG was used as a categorical variable (i.e. 5-9 kg, according to the GWG recommendation of Institute of Medicine for obese women), no association was found.

There are weaknesses as well as strengths in this study. It is possible that a longer follow-up period could indicate more distinct differences in weight and BMI trends. Another weakness is the lack of randomization of the original intervention study. The strength in this case-control study was that we had a participation rate more than $85 \%$ in both study groups. To our knowledge this study is one of few that concerns results from a follow-up of BMI and weight development among offspring to mothers attending a GWG restriction program.

In conclusion, despite a comprehensive gestational intervention program, no differences in BMI or weight development at 5 years of age were observed among the offspring. Prevention against obesity is still an important task. CWC, family planning centres and pre-conception counsellors need to focus on information about the importance of a healthy lifestyle in order to prevent obesity.

\section{Abbreviations}

ANC $=$ Antenatal care clinic, $\mathrm{BMI}=$ Body Mass Index, $\mathrm{CWC}=$ Child welfare centre, GWG $=$ Gestational Weight Gain, WL/H = Weight-for-length/height, ZBMI = Z-score of Body Mass Index, ZWL/H = Z-score of weight-for-length/height 


\section{References}

1. Tsoi E, Shaikh H, Robinson S, Teoh TG. Obesity in pregnancy: a major healthcare issue. Postgrad Med J. 2010 Oct;86[1020]:617-23.

2. Blomberg M. Maternal obesity, mode of delivery, and neonatal outcome. Obstet Gynecol. 2013 Jul;122[1]:50-5.

3. Cnattingius $S$, Villamor $E$, Johansson $S$, et al. Maternal obesity and risk of preterm delivery. JAMA. 2013 Jun 12;309[22]:2362-70.

4. Blomberg M. Maternal and neonatal outcomes among obese women with weight gain below the new institute of medicine recommendations. Obstet Gynecol. 2011 May;117[5]:1065-70.

5. Truong YN, Yee LM, Caughey AB, Cheng YW. Weight gain in pregnancy: does the Institute of Medicine have it right? Am J Obstet Gynecol. 2015 Mar;212[3]:362 e1-8.

6. Oken E. Maternal and child obesity: the causal link. Obstetrics and gynecology clinics of North America. 2009 Jun;36[2]:361-77, ix-x.

7. Li L, Law C, Lo Conte R, Power C. Intergenerational influences on childhood body mass index: the effect of parental body mass index trajectories. Am J Clin Nutr. 2009 Feb;89[2]:551-7.

8. Olson CM, Strawderman MS, Dennison BA. Maternal weight gain during pregnancy and child weight at age 3 years. Matern Child Health J. 2009 Nov;13[6]:839-46.

9. Rooney BL, Mathiason MA, Schauberger CW. Predictors of Obesity in Childhood, Adolescence, and Adulthood in a Birth Cohort. Matern Child Health J. 2011 Oct 7.

10. Reilly JJ, Kelly J. Long-term impact of overweight and obesity in childhood and adolescence on morbidity and premature mortality in adulthood: systematic review. Int J Obes (Lond). 2011 Jul;35[7]:891-8.

11. Solmi F, Morris S. Association between childhood obesity and use of regular medications in the UK: longitudinal cohort study of children aged 5-11 years. BMJ open. 2015;5[6]:e007373.

12. Mustila T, Raitanen J, Keskinen $P$, et al. Lifestyle counseling during pregnancy and offspring weight development until four years of age: follow-up study of a controlled trial. Journal of negative results in biomedicine. 2012;11:11.

13. Mustila T, Raitanen J, Keskinen P, et al. Pragmatic controlled trial to prevent childhood obesity in maternity and child health care clinics: pregnancy and infant weight outcomes (the VACOPP Study). BMC Pediatr. 2013;13:80.

14. Mustila T, Raitanen J, Keskinen $P$, et al. Lifestyle counselling targeting infant's mother during the child's first year and offspring weight development until 4 years of age: a follow-up study of a cluster RCT. BMJ open. 2012;2[1]:e000624.

15. Claesson IM, Sydsjo G, Brynhildsen J, et al. Weight gain restriction for obese pregnant women: a case-control intervention study. BJOG. 2008 Jan;115[1]:44-50.

16. Claesson IM, Sydsjo G, Brynhildsen J, et al. Weight after childbirth: a 2-year follow-up of obese women in a weight-gain restriction program. Acta Obstet Gynecol Scand. 2010 Jan;90[1]:103-10.

17. Claesson IM, Josefsson A, Sydsjo G. Weight six years after childbirth: A follow-up of obese women in a weight-gain restriction programmme. Midwifery. $2013 \mathrm{Jul} 29$.

18. The Public Health Agency of Sweden. Available at http://www.folkhalsomyndigheten.se/documents/smittskyddsjukdomar/vaccinationer/vaccinationsstatistik-barnhalsovarden2014-riket.pdf Retrieved October 2015.

19. Karlberg J, Luo ZC, Albertsson-Wikland K. Body mass index reference values (mean and SD) for Swedish children. Acta Paediatr. 2001 Dec;90[12]:1427-34.

20. Personal communication with Marie Köhler MD, PhD and Carin Oldin MD: Prevalence of overweight and obesity among 4-years-old Swedish children in two different Swedish districts. November 15, 2015. 
21. Ost A, Lempradl A, Casas E, et al. Paternal diet defines offspring chromatin state and intergenerational obesity. Cell. 2014 Dec 4;159[6]:1352-64.

22. Fraser A, Tilling $\mathrm{K}$, Macdonald-Wallis $\mathrm{C}$, et al. Association of maternal weight gain in pregnancy with offspring obesity and metabolic and vascular traits in childhood. Circulation. 2010 Jun 15;121[23]:2557-64.

23. Rasmussen KM, Yaktine AL, Institute of Medicine . Committee to Reexamine IOMPWG. Weight gain during pregnancy : reexamining the guidelines. Washington, DC: National Academies Press; 2009.

24. Tanvig $\mathrm{M}$, Vinter $\mathrm{CA}$, Jorgensen JS, et al. Effects of lifestyle intervention in pregnancy and anthropometrics at birth on offspring metabolic profile at 2.8 years - results from the Lifestyle in Pregnancy and Offspring (LiPO) study. J Clin Endocrinol Metab. 2014 Oct 24:jc20142675.

25. Stamnes Kopp UM, Dahl-Jorgensen K, Stigum H, et al. The associations between maternal pre-pregnancy body mass index or gestational weight change during pregnancy and body mass index of the child at 3 years of age. Int J Obes (Lond). 2012 Oct;36[10]:1325-31.

26. Bammann K, Peplies J, De Henauw S, et al. Early life course risk factors for childhood obesity: the IDEFICS case-control study. PLoS One. 2014;9[2]:e86914.

27. Ensenauer R, Chmitorz A, Riedel C, et al. Effects of suboptimal or excessive gestational weight gain on childhood overweight and abdominal adiposity: results from a retrospective cohort study. Int J Obes (Lond). 2013 Apr;37[4]:505-12. 


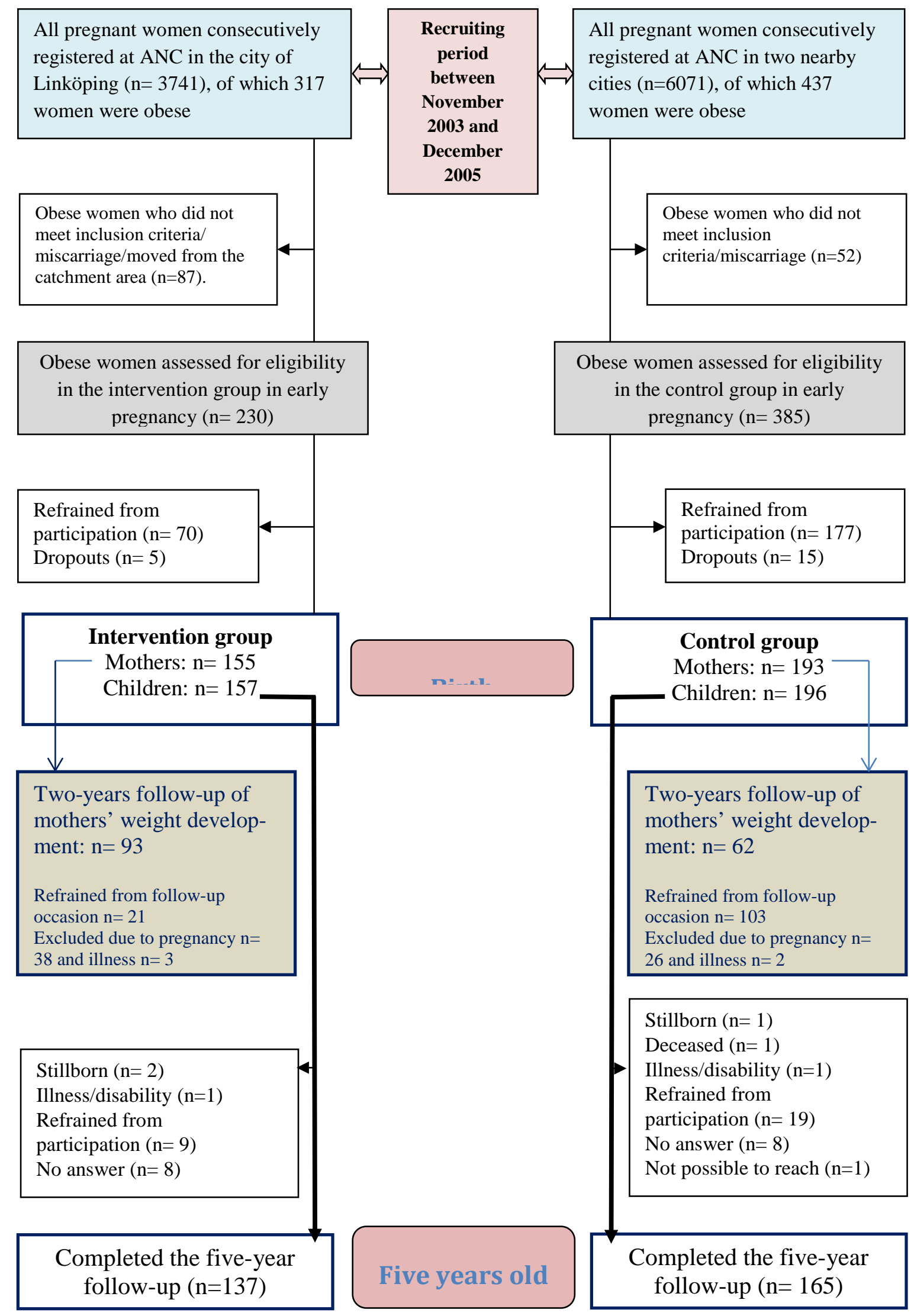

Figure1. Description of the population in the original- and follow-up studies 


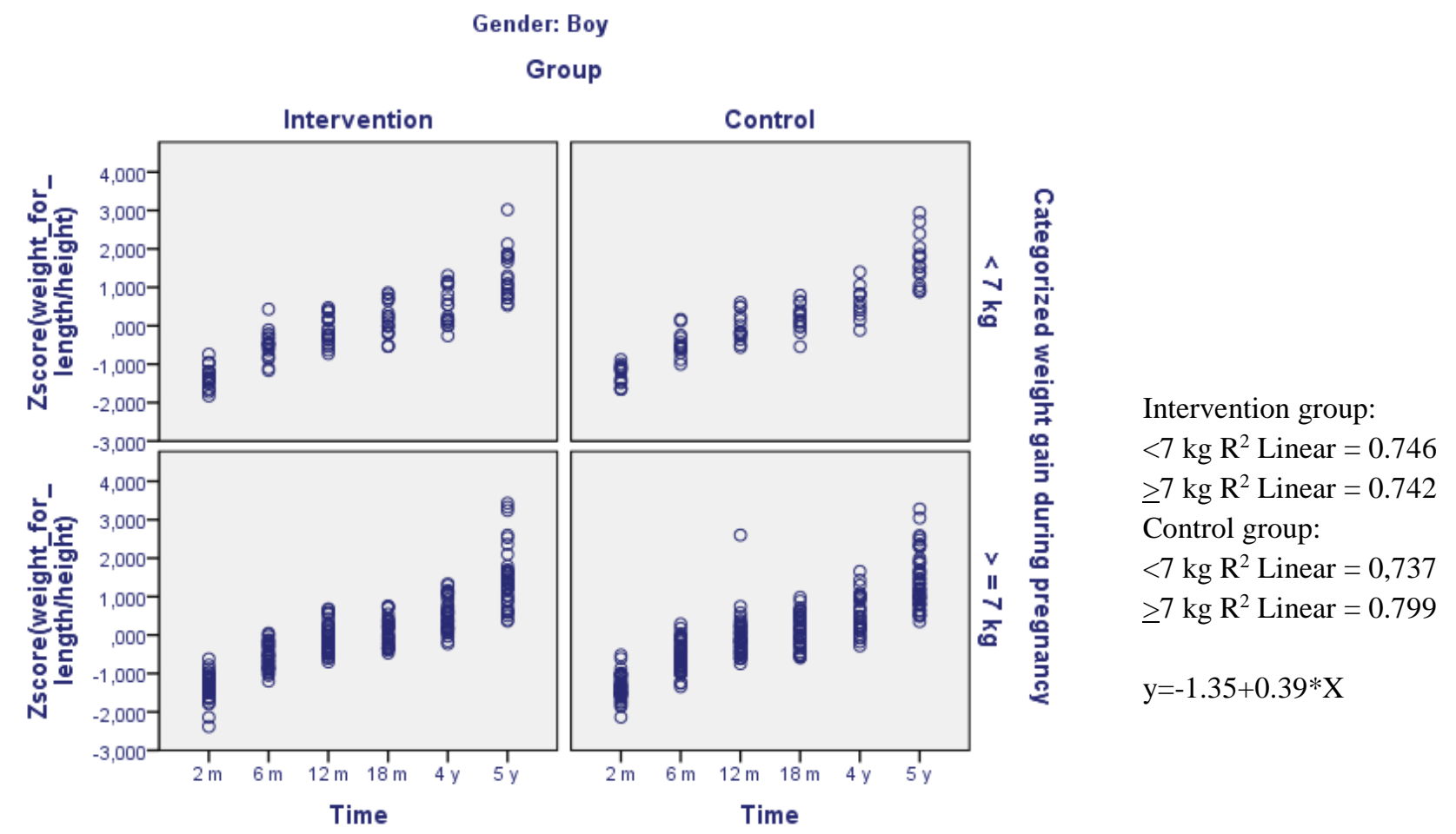

Gender: Girl

Group

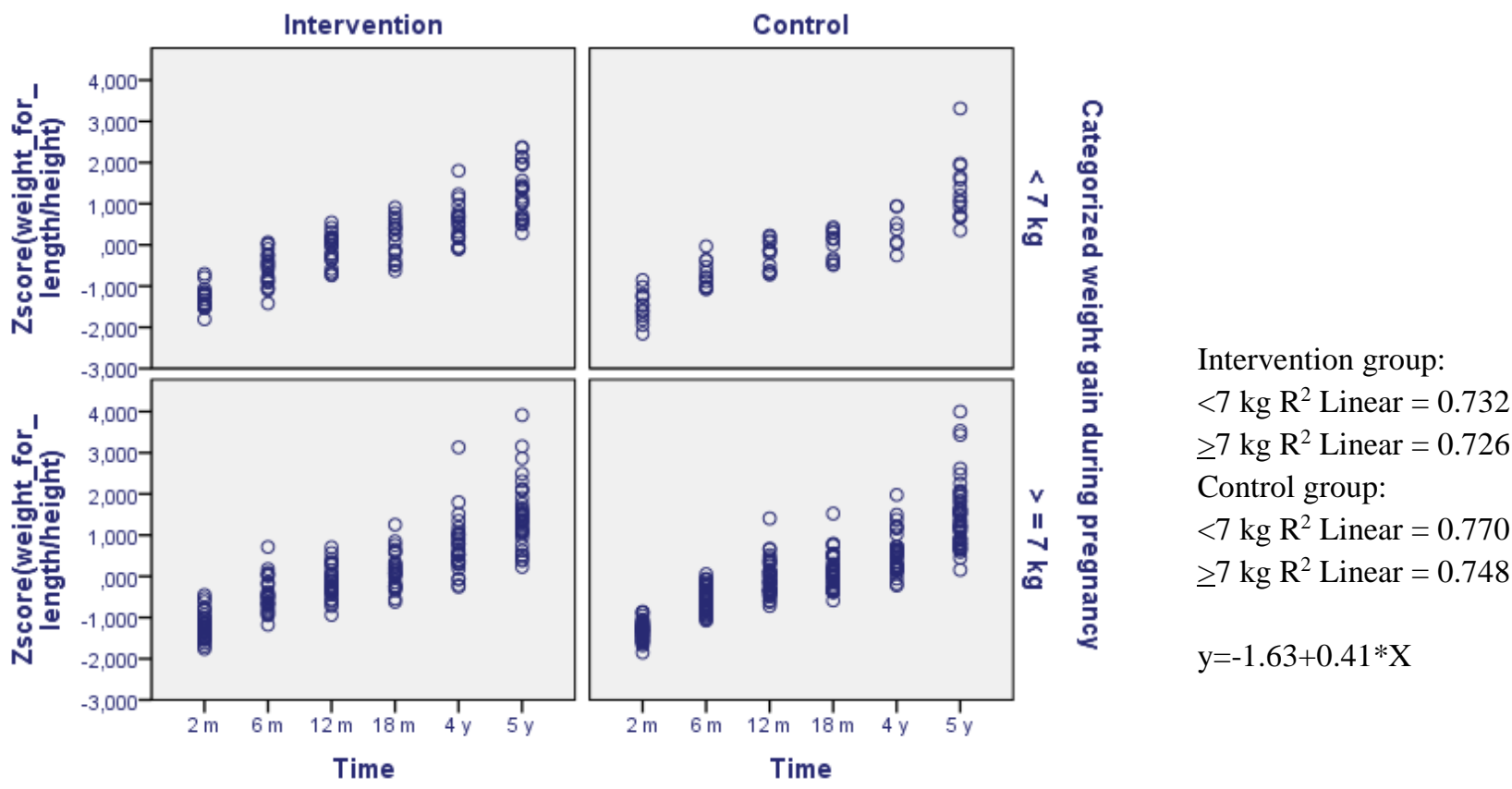

Figure 2. Distribution of standardized scores of weight-for-length/height from two months of age until five years of age among boys and girls in the intervention- and control group 
Table 1. Maternal and children characteristics in the intervention- and control group.

All values are given as frequencies unless otherwise stated.

\begin{tabular}{|c|c|c|c|c|c|}
\hline & \multicolumn{2}{|c|}{ Intervention group } & \multicolumn{2}{|c|}{ Control group } & \multirow[b]{2}{*}{$p^{\mathrm{a}}$} \\
\hline & $\mathbf{n}$ & $\%$ & $\mathbf{n}$ & $\%$ & \\
\hline \multicolumn{6}{|l|}{ Maternal characteristics } \\
\hline Age (mean, SD)* & 135 & $29.8(4.39)$ & 162 & $30.2(4.69)$ & $0.345^{\mathrm{b}}$ \\
\hline Body Mass Index ** & & & & & $0.904^{\mathrm{c}}$ \\
\hline $30.0-34.9$ & 87 & 64.4 & 108 & 66.7 & \\
\hline $35.0-39.9$ & 32 & 23.7 & 37 & 22.8 & \\
\hline$\geq 40$ & 16 & 11.9 & 17 & 10.5 & \\
\hline Parity & & & & & $0.700^{\mathrm{c}}$ \\
\hline First child & 57 & 42.2 & 72 & 44.4 & \\
\hline Second child or more & 78 & 57.8 & 90 & 55.6 & \\
\hline Marital status & & & & & 0.766 \\
\hline $\begin{array}{r}\text { Married/cohabiting with the child's } \\
\text { father }\end{array}$ & 125 & 94.0 & 149 & 93.1 & \\
\hline Other family situation & 8 & 6.0 & 11 & 6.9 & \\
\hline No data available & 2 & & 1 & & \\
\hline Occupation & & & & & 0.358 \\
\hline Gainfully employed & 89 & 66.9 & 115 & 71.9 & \\
\hline Not employed & 44 & 33.1 & 45 & 28.1 & \\
\hline No data available & 2 & & 1 & & \\
\hline $\begin{array}{l}\text { Smoking habits in the home (during } \\
\text { the child's first month of life) }\end{array}$ & & & & & $0.413^{\mathrm{d}}$ \\
\hline No smoking & 107 & 78.1 & 136 & 82.4 & \\
\hline Smoking & 19 & 13.8 & 20 & 12.1 & \\
\hline The mother smoke daily & 7 & 5.1 & 6 & 3.6 & \\
\hline The father smoke daily & 7 & 5.1 & 12 & 7.3 & \\
\hline Both smokes daily & 5 & 3.6 & 2 & 1.2 & \\
\hline No data available & 11 & 8.0 & 9 & 5.5 & \\
\hline $\begin{array}{l}\text { Gestational weight gain in } \mathrm{kg} \text { (mean, } \\
\text { SD);*** }\end{array}$ & 124 & 8.7 (5.43) & 136 & $11.1(5.70)$ & $<0.001^{\mathrm{b}}$ \\
\hline Gestational weight gain $<7 \mathrm{~kg}^{* * *}$ & & & & & $0.005^{\mathrm{c}}$ \\
\hline Yes & 46 & 37.1 & 29 & 21.3 & \\
\hline No & 78 & 62.9 & 107 & 78.7 & \\
\hline \multicolumn{6}{|l|}{ Children characteristics } \\
\hline $\begin{array}{l}\text { Gestational weeks (full weeks) } \\
\text { (mean, SD) }\end{array}$ & 137 & $39.3(2.24)$ & 165 & $39.2(2.07)$ & $0.491^{\mathrm{b}}$ \\
\hline
\end{tabular}




\begin{tabular}{|c|c|c|c|c|c|}
\hline Gestational weeks (full weeks) & & & & & $0.849^{\mathrm{d}}$ \\
\hline$\geq 37$ & 128 & 93.4 & 154 & 93.3 & \\
\hline $33-36$ & 6 & 4.4 & 9 & 5.5 & \\
\hline $28-32$ & 2 & 1.5 & 1 & 0.6 & \\
\hline$<28$ & 1 & 0.7 & 1 & 0.6 & \\
\hline Birth weight in grams (mean, SD) & 137 & 3669.9 (711.25) & 165 & $\begin{array}{c}3659.2 \\
(562.94)\end{array}$ & $0.451^{\mathrm{b}}$ \\
\hline $\begin{array}{l}\text { Children with diagnosis small for } \\
\text { gestational age }\end{array}$ & & & & & $0.231^{\mathrm{d}}$ \\
\hline No & 134 & 97.8 & 164 & 99.4 & \\
\hline Yes & 3 & 2.2 & 1 & 0.6 & \\
\hline $\begin{array}{l}\text { Children with diagnosis large for } \\
\text { gestational age }\end{array}$ & & & & & $0.634^{\mathrm{c}}$ \\
\hline No & 125 & 91.2 & 153 & 92.7 & \\
\hline Yes & 12 & 8.8 & 12 & 7.3 & \\
\hline $\begin{array}{l}\text { Macrosomia, } \\
\text { birth weight }>4500 \mathrm{~g}\end{array}$ & & & & & $0.993^{\mathrm{c}}$ \\
\hline No & 127 & 92.7 & 153 & 92.7 & \\
\hline Yes & 10 & 7.3 & 12 & 7.3 & \\
\hline Gender & & & & & $0.652^{\mathrm{c}}$ \\
\hline Female & 70 & 51.1 & 80 & 48.5 & \\
\hline Male & 67 & 48.9 & 85 & 51.5 & \\
\hline Breastfed child (any time) & & & & & $0.013^{\mathrm{d}}$ \\
\hline Yes & 136 & 99.3 & 154 & 93.3 & \\
\hline No & 0 & 0.0 & 7 & 4.2 & \\
\hline No data available & 1 & 0.7 & 4 & 2.4 & \\
\hline $\begin{array}{l}\text { Duration of total breastfeeding } \\
\text { (month) }\end{array}$ & & & & & $0.771^{\mathrm{c}}$ \\
\hline$>12$ & 20 & 14.6 & 17 & 10.3 & \\
\hline 6-11 & 54 & 39.4 & 65 & 39.4 & \\
\hline 3-5 & 31 & 22.6 & 33 & 20.0 & \\
\hline$<3$ & 31 & 22.6 & 39 & 23.6 & \\
\hline 0 & 0 & 0.0 & 7 & 4.2 & \\
\hline No data available & 1 & 0.7 & 4 & 2.4 & \\
\hline $\begin{array}{l}\text { Duration of exclusive breastfeeding } \\
\text { (months) }\end{array}$ & & & & & $0.266^{\mathrm{c}}$ \\
\hline 4-6 & 72 & 52.6 & 74 & 44.8 & \\
\hline $1-3$ & 20 & 14.6 & 31 & 18.8 & \\
\hline$<1$ & 18 & 13.1 & 15 & 9.1 & \\
\hline 0 & 26 & 19.0 & 41 & 24.8 & \\
\hline No data available & 1 & 0.7 & 4 & 2.4 & \\
\hline
\end{tabular}


${ }^{\mathrm{a}}$ Missing data are not included in the analyses ${ }^{\mathrm{b}}$ Mann-Whitney U test $\quad{ }^{\mathrm{c}}$ Pearson Chi-squaretest ${ }^{\mathrm{d}}$ Fischer's Exact Test

* Age at childbirth

** Body Mass Index in early pregnancy

*** Only women with simplex pregnancies are included. Weight registered in the same week as the delivery. If this value was missing, the weight was measured 1 or 2 weeks before the delivery 
Table 2. Body Mass Index (BMI) and standard score of Body Mass Index (ZBMI) for girls and boys in the intervention- and control group

\begin{tabular}{|c|c|c|c|c|c|c|c|c|c|c|c|c|c|c|}
\hline & \multicolumn{3}{|c|}{ Intervention group } & \multicolumn{3}{|c|}{ Control group } & \multirow[b]{2}{*}{$\mathrm{p}^{*}$} & \multicolumn{3}{|c|}{ Intervention group } & \multicolumn{3}{|c|}{ Control group } & \multirow[b]{2}{*}{$\mathrm{p}^{*}$} \\
\hline & $\mathrm{n}$ & mean & SD & $\mathrm{n}$ & mean & SD & & $\mathrm{n}$ & mean & SD & $\mathrm{n}$ & mean & SD & \\
\hline BMI at 5 years of age & 70 & 16.7 & 1.935 & 78 & 16.3 & 1.968 & 0.139 & 65 & 16.7 & 1.866 & 85 & 16.6 & 1.687 & 0.783 \\
\hline BMI at 5 years of age & 36 & 16.8 & 1.958 & 52 & 16.5 & 2.114 & 0.348 & 41 & 16.8 & 2.008 & 53 & 16.5 & 1.748 & 0.626 \\
\hline ZBM at 5 years of age & 36 & 0.142 & 1.055 & 52 & -0.047 & 1.138 & 0.348 & 41 & 0.111 & 1.081 & 53 & -0.027 & 0.942 & 0.626 \\
\hline \multicolumn{15}{|c|}{$\begin{array}{l}\text { Children of mothers with } \\
\text { gestational weight gain }<7 \mathrm{~kg}^{* *}\end{array}$} \\
\hline
\end{tabular}

* Mann Whitney U-test

** Only women with simplex pregnancies are included. Weight registered in the same week as the delivery. If this value was missing, the weight was measured 1 or 2 weeks before the delivery

$\dagger$ After adjusting for socio-demographic factors and breastfeeding $\mathrm{p}=0.407$ 
Table 3. Distributions of Body Mass Index values among girls and boys in the intervention- and control group at five years of age. According to Body Mass Index reference values (mean and SD) for Swedish children

\begin{tabular}{|c|c|c|c|c|c|c|c|c|c|c|}
\hline & \multicolumn{5}{|c|}{ Girls } & \multicolumn{5}{|c|}{ Boys } \\
\hline & \multicolumn{2}{|c|}{ Intervention group } & \multicolumn{2}{|c|}{ Control group } & \multirow[b]{2}{*}{$\mathrm{p}^{*}$} & \multicolumn{2}{|c|}{ Intervention group } & \multicolumn{2}{|c|}{ Control group } & \multirow[b]{2}{*}{$\mathrm{p}^{*}$} \\
\hline & $\mathrm{n}$ & $\%$ & $\mathrm{n}$ & $\%$ & & $\mathrm{n}$ & $\%$ & $\mathrm{n}$ & $\%$ & \\
\hline & & & & & 0.318 & & & & & 0.778 \\
\hline$+3 \mathrm{SD}$ & 2 & 2.9 & 4 & 5.1 & & 4 & 6.2 & 3 & 3.5 & \\
\hline$+2 \mathrm{SD}$ & 7 & 10.0 & 1 & 1.3 & & 6 & 9.2 & 10 & 11.8 & \\
\hline$+1 \mathrm{SD}$ & 17 & 24.3 & 20 & 25.6 & & 12 & 18.5 & 18 & 21.2 & \\
\hline Mean & 37 & 52.9 & 44 & 56.4 & & 38 & 58.5 & 47 & 55.3 & \\
\hline$-1 \mathrm{SD}$ & 6 & 8.6 & 8 & 10.3 & & 4 & 6.2 & 7 & 8.2 & \\
\hline$-2 \mathrm{SD}$ & 1 & 1.4 & 1 & 1.3 & & 1 & 1.5 & 0 & 0.0 & \\
\hline$-3 \mathrm{SD}$ & 0 & 0.0 & 0 & 0.0 & & 0 & 0.0 & 0 & 0.0 & \\
\hline & & & & & & & & & & \\
\hline
\end{tabular}

* Chi-2-test 